\title{
ИНФОРМАЦИОННЫЕ ТЕХНОЛОГИИ: ПРОШЛОЕ, НАСТОЯЩЕЕ, БУДУЩЕЕ
}

Волков В.Э. ${ }^{1}$

${ }^{1}$ Одесская национальная академия пищевых технологий, Одесса

Copyright (C) 2014 by author and the journal "Automation technological and business - processes".

This work is licensed under the Creative Commons Attribution International License (CC BY).

http://creativecommons.org/licenses/by/4.0/
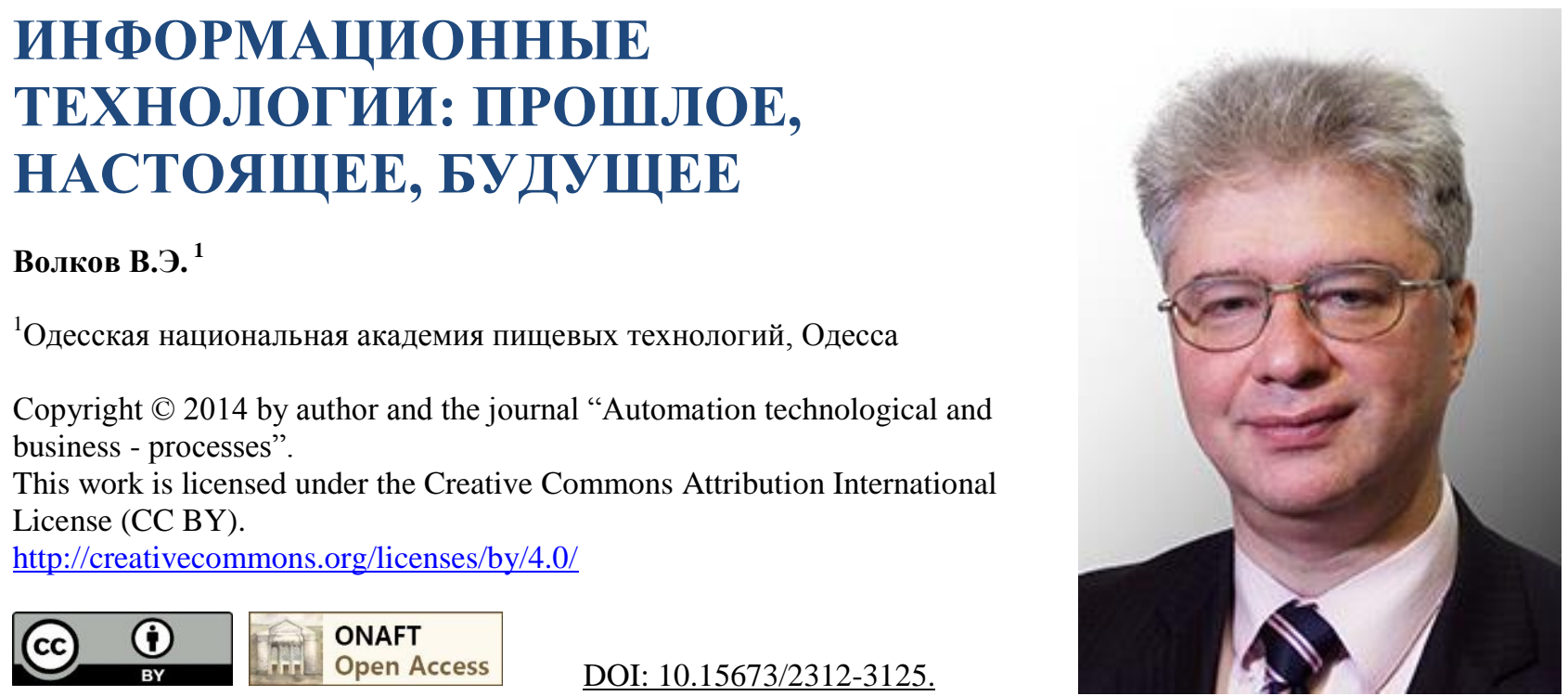

\begin{abstract}
Аннотация
Вкратце изложена история развития информационных технологий и компьютерной техники. Изложение носит не вполне традиционный и неформальный характер. Особое внимание уделено прямой взаимосвязи уровня развития информационных технологий с достижениями технического прогресса, подчеркнут «электронно-компьютерный» характер современной информационно-коммуникационной технологии. Детально рассмотрен вопрос о поколениях ЭВМ; показано, что компьютеры пятого поколения не созданы до сих пор. Показана тесная взаимосвязь информатики и кибернетики (при отсутствии тождественности этих наук). Автоматизация трактуется как «пратическая кибернетика» или прикладная кибернетика. Рассмотрены современное состояние и перспективы развития информационных технологий. Указано на особую роль смартфонов и фотонных компьютеров в недалеком будущем.
\end{abstract}

\section{Abstract}

History of information technology and computing machinery expounded in brief. Summary is done not quite traditionally and in informal way. Special attention has been given to the interrelation between the information technology level and general technological advancements, «electronic» and «computer» features of the modern information and communication technology are emphasized. The question of the computer generations is considered in details; it is proved that so-called «the fifth generation computer» does not exist yet. Strong interrelation between informatics and cybernetics is demonstrated (but those branches of science are not exactly the same). Automation is interpreted as «practical cybernetics» or applied cybernetics. The modern state and the prospects for the development are considered. The exclusive role for smartphones and photonic computer is indicated.

\section{Ключевые слова}

Информация, информационная технология, информационно-коммуникационная технология, информатика, кибернетика, системный анализ, искусственный интеллект, автоматизация, управление, компьютер. 


\section{ОГЛЯДИ ТА РЕКЛАМНІ МАТЕРІАЛИ}

\section{Введение}

Настоящая статья представляет собой не столько научную, сколько научно-популярную работу, которая преследует три цели::

1) рассмотреть историю развития информационных технологий с позиций их нынешнего состояния и сквозь призму общих исторических процессов;

2) определить ключевые области приложения современных информационных технологий;

3) указать возможные приоритетные пути развития информационных технологий в ближайшем будущем.

Ряд утверждений, высказанных ниже, отражают не столько общепринятую точку зрения, сколько субъективный взгляд автора и носят дискуссионный характер. Однако такого рода субъективизм в принципе неизбежен, когда речь идет об историческом анализе или о прогнозах на будущее. Кроме того, речь идет о «молодых» науках с нечетко очерченным предметом исследования и неустоявшейся терминологией, а подобные неопределенности вынуждают автора к субъективизму, так как «объективный» взгляд на ряд проблем попросту невозможен.

\section{Вопросы терминологии}

Под информационной технологией (Information Technology, IT) в дальнейшем понимается технология накопления, хранения, обработки и передачи информации; при этом предполагается, что смысл терминов «технология» и «информация» очевиден (хотя понятие информации по уровню общности близко к философской категории). Ключевым словом в приведенном выше определении является слово «обработка», поэтому определение можно сократить: информационная технология - технология обработки информации. Когда говорится об «информационных технологиях» во множественном числе, то подразумеваются различные виды и формы единой (вообще говоря) информационной технологии. Попутно отметим, что общеупотребимый в современном мире термин «IT-технологии» - тавтологичен. Авторы, которые особый упор делают не на обработку, а на передачу информации (хотя передача информации без ее определенной обработки невозможна), говорят не об информационных, а о информационно-коммуникационных технологиях. В контексте вышесказанного термины «информационная технология» и «информационно-коммуникационная технология» синонимичны. Если же акцентировать внимание исключительно на технологии передачи информации, то наилучшим термином является «коммуникационная технология».

Информационная технология включает в себя методы обработки информации, организационноуправленческие концепции ее формирования и потребления, а также совокупность всех видов информационной и коммуникационной техники.

Под информатикой будем понимать науку (точнее, комплекс наук), изучающую информационные технологии. Термин «информатика» употребляется преимущественно в странах СНГ и во Франции. Сама этимология этого термина (по крайней мере, в русскоязычной литературе) остается неясной; по одной из версий, слово «информатика» - русская «калька» с французского слова informatique, возникшего как объединение 2-х других французских слов: information (информация) и automatique (автоматика), причем во Франции термин informatique официально вошел в употребление с 1966 г.; по другой версии, термин «информатика» - результат словообразования «информация» + «математика», автором которого является советский академик Андрей Петрович Ершов (1931-1988 гг.), возглавлявший некоторое время отдел теоретического программирования Вычислительного центра АН СССР, причем, возможно, английское слово informatics есть именно «калька» с русского. Кроме того, принято считать, что в английский язык термин «informatics» ввёл (возможно, независимо от остальных) Уолтер Ф. Бауэр (Walter F. Bauer) - один из пионеров компьютерной техники в США, соучредитель фирмы «Informatics Inc.». В англо-американском мире преобладает, однако, термин computer science, что означает буквально «компьютерная наука». Термин «информатика» представляется нам все же более удачным, так как охватывает и те области обработки информации, которые не связаны с компьютерами (хотя, бесспорно, в современном мире информатика без компьютерной техники немыслима).

В информатике (в «компьютерной науке») всегда выделяли техническую (hardware) и программную (software) отрасли. Однако, постепенно из программной отрасли выделилась алгоритмическая (brainware); грань между ними, естественно, нечеткая, но все же присутствует: brainware - удел математиков, а software - программистов. Кроме того, в последнее время все больший удельный вес приобретает организационная отрасль (orgware).

Информатика (естественно, достаточно условно) подразделяется на теоретическую и прикладную. 
Теоретическая информатика включает в себя ряд разделов; по определению Ассоциации вычислительной техники (Association for Computing Machinery, ACM) особо выделяются 4-ре области - теория вычислений, алгоритмы и структуры данных, методология программирования и языки программирования, компьютерные элементы и архитектура вычислительных систем; кроме того, важнейшими направлениями теоретической информатики являются компьютерные сети и телекоммуникации, операционные системы, разработка программного обеспечения, системы управления базами данных, параллельные вычисления, распределённые вычисления, числовые и символьные вычисления, взаимодействия между человеком и компьютером, компьютерная графика (хотя прикладной аспект всех этих направлений вполне очевиден).

Прикладная информатика направлена на выявление определённых понятий в области информатики, которые могут быть использованы для решения стандартных практических задач. Прикладная информатика объединяет конкретные примеры применения информатики в тех или иных областях науки или производства. Так возникли, например, бизнес-информатика, педагогическая информатика и информационная педагогика, геоинформатика, компьютерная лингвистика, биоинформатики, хемоинформатика (химическая информатика или же молекулярная информатика) и т. д. Интересно, что в США, где термин «informatics» сам по себе используется редко (см. выше), его применение в настоящее время связано главным образом именно с прикладными разделами информатики: «bioinformatics», «geoinformatics» и т. п. [1].

Под кибернетикой будем понимать науку об общих законах управления любыми системами (кроме, быть может, социальных), выделяя, однако, управление техническими системами. Собственно говоря, само слово

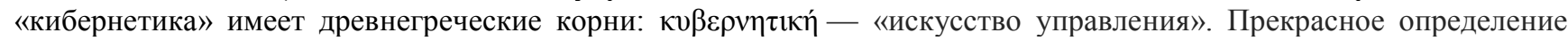
кибернетике дал советский математик, член-корреспондент АН СССР Алексей Андреевич Ляпунов (1911-1973 гг.), он определил кибернетику как «науку об общих закономерностях строения управляющих систем и течения процессов управления» [2].

«Отцом» современной кибернетики справедливо считают американского ученого Норберта Винера (Norbert Wiener) (1894-1964 гг.), выпустившего в свет в 1948 г. книгу «Кибернетика, или управление и связь в животном и машине» («Cybernetics, or Control and Communication in the Animal and the Machine») [3]. Основной тезис книги подобие процессов управления и связи в технических устройствах (машинах), живых организмах (включая человека) и обществах, будь то общества животных или человеческие (последнее утверждение и по сей день вызывает жаркие споры!!!). Процессы эти прежде всего являются процессами передачи, хранения и переработки информации, именно поэтому кибернетика и информатика теснейшим образом взаимосвязаны. Винер развивал селективную концепцию информации, когда любой сигнал, любую информацию, независимо от ее конкретного содержания и назначения, можно рассматривать как некоторый выбор между двумя или более значениями, наделенными известными вероятностями, что позволяет подойти ко всем процессам с единым статистическим аппаратом. Отсюда и мысль Винера об общей теории управления и связи - кибернетике. По Винеру, количество информации является, подобно количеству энергии и вещества, одной из фундаментальных явлений природы. Винер [3] и вслед за ним Леон Николя Бриллюен (Léon Nicolas Brillouin) [4,5], основатель современной физики твёрдого тела, отождествляли количество информации с отрицательной энтропией (негэнтропией). Это приводит к толкованию кибернетики как теории организации, теории борьбы с возрастанием энтропии [3]. В соответствии с теорией Винера, действующий объект поглощает информацию из внешней среды и использует ее для «правильного» поведения; информация не создается, она только передается и принимается, но при этом может утрачиваться (исчезать) - информация искажается помехами («шумом») на пути к объекту и внутри него, вследствие чего утрачивается для этого объекта; таким образом, борьба с ростом энтропии - это борьба с щумом, искажающим информацию.

Книга Винера, однако, не содержала последовательного курса кибернетики: это был только проект. После выхода книги кибернетика нашла как горячих сторонников, так и столь же горячих противников. Но к концу 1950 ых годов кибернетика стала признанным (причем популярным!) направлением науки, с широкими задачами и многообразным инструментарием. Начался период систематического построения кибернетики, создания и изложения ее логической системы (эта задача остается актуальной по сей день, так как кибернетика и сейчас выглядит скорее областью исследований, чем вполне упорядоченной, сложившейся наукой - общепризнанного, последовательного изложения кибернетики как отдельной дисциплины все еще нет!).

Винер связывал кибернетику со статистической физикой; позднейшие авторы большей частью предпочитают излагать кибернетику абстрактно, отвлекаясь от энергетической стороны процессов. Таким образом «общая» кибернетика отделяется от «термодинамической кибернетики» (выражение Г.Н. Поварова, редактора русского перевода винеровской «Кибернетики» и автора предисловия к этой книге [3]) Винера. 


\section{ОГЛЯДИ ТА РЕКЛАМНІ МАТЕРІАЛИ}

Английский психиатр и нейрофизиолог Уильям Росс Эшби (William Ross Ashby) указал на общую теорию динамических систем как логическое основание кибернетики [6,7]. Той же точки зрения придерживался и председатель Научного совета по кибернетике при АН СССР академик Аксель Иванович Берг, который писал: «Кибернетика - это наука об управлении сложными динамическими системами. Термин «сложность» здесь применяется как философская категория. Динамические системы на производстве, в природе и в человеческом обществе - это системы, способные к развитию, к изменению своего состояния. Сложные динамические системы образуются множеством более простых или элементарных систем или элементов, взаимосвязанных и взаимодействующих» [8]. Аналогичный подход присутствует и в статье Розенблюта, Винера и Бигелоу «Поведение, целенаправленность и телеология» (1943г.) [3,9]. Все это роднит кибернетику с общей теорией систем и с системным анализом в широком смысле слова [10], а также с тектологией Александра Александровича Богданова [11,12] как с предшественницей этого научного направления.

При всей широте научных проблем, охватываемых кибернетикой, одна из них играет особую роль - это проблема искусственного интеллекта. Именно к этой проблеме многие авторы [13] сводят кибернетику «в узком смысле этого слова». При этом существуют по меньшей мере три категории кибернетических задач [13]:

1) создание искусственного интеллекта и его использование в системах автоматического управления (САУ) независимо от того, каким может оказаться его соотношение с разумом и способностями человека;

2) создание искусственного интеллекта, являющегося функциональной копией поведения человека или животного (имитация);

3) создание искусственного интеллекта и воспроизведение различных аспектов поведения организмов на основе использования материалов аналогичных тем (если не тех же самых) из которых построены живые организмы.

Первый класс кибернетических задач в настоящее время представляет наибольший интерес с практической точки зрения, так как служит источником для главного приложения кибернетики - автоматизации.

Автоматизация представляет собой комплекс мер по замене интеллектуальной (рассудочной) деятельности человека работой технических средств (в отличие от механизации, которая представляет собой комплекс мер по замене затрат мышечной энергии человека или животного работой технических средств, - «механизмов», питающихся от «искусственных» источников энергии). Таким образом, автоматизация есть важнейшая составляющая прикладной кибернетики (на наш взгляд на сегодняшний день почти правомерно отождествление автоматизации с прикладной кибернетикой). Очевидно, что эффективность автоматизации тем выше, чем выше уровень «интеллекта» технических средств управления.

А.А. Ляпунов особо подчеркивал взаимосвязь кибернетики с «компьютерной наукой» и значение автоматизации как прикладного аспекта кибернетики [2,14,15]. По Ляпунову, основным вопросом, в связи с которым формируется кибернетика, является вопрос о взаимоотношении возможностей вычислительной машины и (человеческого) мышления. Вычислительная машина и мышление представляют собой две управляющие системы с очень широкими возможностями, но в некотором смысле крайних типов: вычислительная машина - это управляющая система, действующая строго формально, по заданному алгоритму; мышление - это управляющая система, функционирование которой совсем не формализовано. Для того, чтобы реализовать в вычислительной машине некоторый процесс управления, т.е. соответствующий процесс переработки информации, необходимо смоделировать исходный процесс и оценить качество приближения [14]. Понятие управляющей системы чрезвычайно широко и охватывает объекты традиционно или по существу не относящиеся к кибернетике, поэтому Ляпунов выделяет подмножество «кибернетических управляющих систем» [15], причем такое выделение производится в соответствии с тремя признаками: дискретностью, сложностью системы и многозначностью представлений [2,14,15].

Изучение управляющих систем возможно с двух позиций: макроподхода и микроподхода [15]. При макроподходе управляющая система рассматривается как «черный ящик», внутреннее строение которого неизвестно. Основная задача макроподхода - «раскрыть объект как управляющую систему» [15]. При этом синтезируется математическое описание объекта, необходимое для последующих кибернетических рассмотрений. Микроподход предусматривает расчленение управляющей системы на элементарные управляющие системы, существенная сложность затрудняет прослеживание макросвойств от микросвойств управляющей системы.

Макроподход включает четыре основные направления кибернетических исследований [15]: 1) выяснение потоков информации; 2) раскрытие кодов информации; 3) выявление функций управляющей системы; 4) изучение функционирования управляющей системы.

Микроподход включает еще восемь направлений [15]:

- выявление элементов управляющих систем; 


\section{ОГЛЯДИ ТА РЕКЛАМНІ МАТЕРІАЛИ}

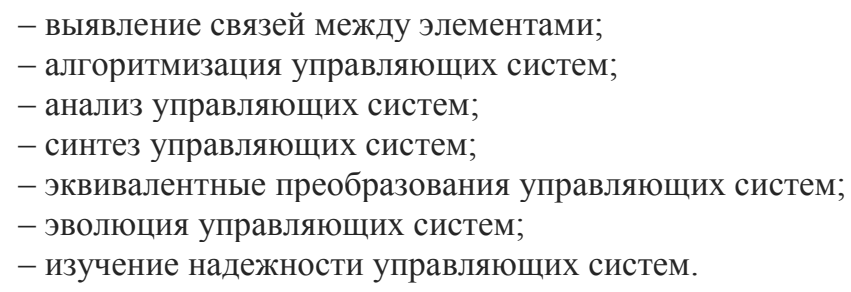

Этапы развития и особенности информационной технологии

По применяемому инструментарию в развитии информационной технологии можно выделить следующие этапы, границы межу которыми достаточно условны и размыты.

«Нулевой» этап - со времени появления «человека разумного» или homo sapiens (около 100 тыс. лет назад) до возникновения письменности (ориентировочно V-ое тысячелетие до н. э.). Этот этап можно было бы назвать доисторическим, так как изначально история как наука формировалась в результате анализа разнообразных nисьменных источников. На этом этапе накопление и сохранение информации осуществлялось исключительно с помощью человеческого мозга (с использованием памяти как одной из высших психических функций), а передача информации - с помощью жестов и речи. Многие авторы вообще не упоминают об этом этапе в развитии информационной технологии. На наш взгляд это не совсем корректно по двум причинам:

во-первых, с появлением «человека разумного» возникла необходимость в накоплении, сохранении и передаче информации, т.е. так или иначе реализовывалась (пусть даже самая примитивная!) информационная технология; иными словами, информационная технология - «ровесница» и атрибут homo sapiens;

во-вторых, на этом этапе интенсивно (хотя и стихийно) развивались искусство запоминания (мнемоника) и искусство речи как способа передачи информации; оба данных направления человеческой деятельности развиваются и совершенствуются по сей день, не утратив актуальности.

Основная цель информационной технологии на «нулевом» этапе ее развития состоит в простом сохранении информации и передаче ее без существенных потерь или отклонений от исходной.

Первый этап - со времени возникновения письменности до возникновения книгопечатания (в Европе - конец XVI-начало XVII вв.). Этап «ручной» информационной технологии, когда основным инструментарием были бумага, перо и чернильница, коммуникации осуществлялись посредством писем, а информация накапливалась и хранилась в виде рукописей.

Письменностью принято называть некоторую знаковую систему, предназначенную для формализации, фиксации и передачи тех или иных данных (как правило - речевой информации). Письменность считается одной из основных форм существования человеческого языка. Невозможно даже более или менее точно указать, где и когда впервые возникла письменность. И причина не только в хронологических проблемах, а в первую очередь в том, что современная письменность прошла достаточно длительный период становления, в котором можно выделить ряд этапов, - предметное письмо, пиктографическое («рисуночное») письмо, идеография («письмо по понятиям»), иероглифическое, слоговое и алфавитное письмо, - причем не вполне ясно, например, можно ли считать письменностью предметное письмо (ответ подавляющего большинства лингвистов и историков отрицательный) и пиктографию (ответ для многих исследователей положительный). Самые ранние пиктограммы обнаружены в одной из древних культур Передней Азии (регион Сирии-Израиля) и относятся к $9000-7000$ гг. до н. э.; к VI тыс. до н. э. отнесены древнейшие китайские иероглифы, обнаруженные на панцирях черепах в 1962 г. при раскопках неолитического поселения Цзяху на реке Хуанхэ; в IV тыс. до н. э. в Междуречье развивается клинопись (пиктографическое письмо); примерно в конце IV тыс. до н. э. в Древнем Египте возникают законченная форма иероглифического письма (первая «настоящая» письменность) и иератическое письмо (скоропись), почти тогда же в северо-западном Индостане возникает древнейший известный алфавит - «письменность долины Инда»; ок. 1000 г. до н. э. возникает финикийский алфавит, от которого происходят греческая и латинская письменность.

Возникновение письменности обусловило качественно новые возможности долговременного хранения больших объемов информации и существенно повысило надежность коммуникационной технологии.

Основная цель «ручной» информационной технологии - представление информации в нужной форме.

Второй этап - этап «механической» информационной технологии, от времен возникновения книгопечатания до второй половины ХІХ в. включительно. 
Книгопечатание фактически было изобретено дважды: в Китае и в средневековой Европе. В Китае книгопечатание возникло не позднее X в., а в Европе способ книгопечатания подвижными литерами изобрел немецкий ювелир Иоганн Гуттенберг в 1440-е годы. Книгопечатание - громадный шаг вперед на пути механизации и автоматизации процесса накопления, хранения и передачи информации. Наряду с книгами появляются газеты и другие периодические издания.

Во второй половине XIX в. возникают механические пишущие машинки и телеграф, происходит модернизация системы общественной почты. Все это послужило базой для принципиальных изменений в технологии обработки информации и, как следствие, продуктивности работы. По существу, «механическая» информационная технология проложила дорогу к формированию организационной структуры современных учреждений.

Основная цель «механической» информационной технологии - представление информации в нужной форме более удобными средствами.

Третий этап - этап «электрической» или, точнее, «электромеханической» информационной технологии, продолжительностью менее 100 лет - с конца XIX-го и до середины XX-го века. В этот период интенсивно развиваются телефонная и радиосвязь, механические пишущие машинки заменяются электрическими, возникают магнитофоны и диктофоны (в т.ч. портативные). Учрежденческая деятельность многократно улучшилась за счет повышения количества, качества и скорости обработки документов.

Акцент в информационной технологии начинает перемещаться с формы представления информации на формирование ее содержания.

Четвертый этап - этап «электронной» или «компьютерной» информационной технологии, с середины $\mathrm{XX}$-го века (появление первых электронно-вычислительных машин) и до наших дней. Возникновение телевидения и компьютеров принципиально изменило информационно-коммуникационную технологию. В настоящее время основным инструментарием компьютерной технологии является персональный компьютер с широким спектром программных продуктов разнообразного назначения. Широко используются локальные и глобальные компьютерные сети; особую роль приобрела мировая сеть Internet. Приобретен огромный опыт формирования содержательной стороны информации.

Еще раз подчеркнем, что как периодизация, так и само обозначение этапов развития информационной технологии носят весьма условный и субъективный характер.

Одна из особенностей развития информационной технологии состоит в том, что на каждом следующем этапе в значительной степени сохраняется инструментарий предыдущих этапов.

Принципиальное отличие информационной технологии от производственной состоит в том, что информационная технология не может быть непрерывной, так как она всегда соединяет работу рутинного типа и работу творческую, пока не поддающуюся формализации. Из всех видов технологий информационная технология предъявляет самые высокие требования к «человеческому фактору».

\section{Поколения ЭВМ и развитие компьютерной техники}

Первые электронно-вычислительные машины (ЭВМ) или компьютеры были созданы в 30-ые - 40-ые гг. XX-го века. Их появление, собственно говоря, и знаменовало начало современного этапа развития информационных технологий.

По элементной базе можно выделить четыре поколения ЭВМ.

Первое поколение - ЭВМ на электронных лампах (середина 1940-ых - середина 1950-ых годов). Первый универсальный ламповый компьютер ENIAC («Electronic Numerical Integrator and Computer»), сконструированный американским инженером-электронщиком Джоном Эккертом (Eckert) и американским физиком Джоном Моучли (Mauchly) и предназначенный в первую очередь для решения задач баллистики, имел почти 20 тыс. электронных ламп и 1,5 тыс. реле, потребляя мощность до 150 кВт.

Переход ко второму поколению ЭВМ стал возможен после 1948 г., когда американские физики Уолтер Брайттен (Brattain), Джон Бардин (Bardeen) и Уильям Шокли (Shockley) сконструировали транзистор (в 1956 г. им за это изобретения и за исследования в области полупроводников, начатые в 1945 г. была присуждена нобелевская премия).

Второе поколение - ЭВМ на транзисторах (середина 1950-ых - середина 1960-ых годов). Первый компьютер на транзисторах NCR-304 был создан фирмой NCR (США) в 1954-1957 гг.; широкое распространение подобные компьютеры получили к 1960 г.; компьютер IBM 1620 на транзисторах, ставший заменой ламповому IBM 650, был размером с офисный стол; однако компьютеры второго поколения (как и компьютеры первого) по-прежнему были довольно дороги и поэтому использовались только университетами, правительствами и крупными корпорациями. 
Прелюдией к появлению компьютеров третьего поколения стало сразу несколько событий. В 1952 г. британский инженер-радиотехник Джеффри Даммер (Dummer) на конференции в Вашингтоне впервые предложил совершенно новую идею интеграции множества стандартных электронных компонентов в монолитном кристалле полупроводника. Всего год спустя Харвик Джонсон (Johnson) подал первую в истории патентную заявку на прототип интегральной схемы (ИС). Однако реализация этих предложений в те годы не могла состояться из-за недостаточного развития технологий. В конце 1958 и в первой половине 1959 гг. в полупроводниковой промышленности состоялся прорыв. Джек Килби (Kilby) из фирмы Техаs Instruments запатентовал принцип интеграции, создал первые несовершенные прототипы ИС и довёл их до серийного выпуска. Курт Леговец (Lehovec) из Sprague Electric Company изобрёл способ электрической изоляции компонентов, сформированных на одном кристалле полупроводника. Роберт Нойс (Noyce) из Fairchild Semiconductor изобрёл способ электрического соединения компонентов ИС (металлизацию алюминием) и предложил усовершенствованный вариант изоляции компонентов на базе новейшей планарной технологии Жана Эрни (Hoerni). 27 сентября 1960 года группа Джея Ласта (Last) создала в компании «Fairchild Semiconductor» первую работоспособную полупроводниковую ИС по идеям Нойса и Эрни. В будущем Роберт Нойс стал одним из основателей фирмы Intel.

В 1961 г. в продажу поступила первая выполненная на пластине кремния ИС, содержащая триггер на 6 элементах (4 биполярных транзистора и 2 резистора). К 1963 г. ИС имела 10-20 элементов, к 1982 г. - примерно 100, к 1970 г. - 1000, к 1975 г. - 30000, к 1982 г. - 300000 элементов на кристалле в несколько квадратных миллиметров.

Третье поколение - ЭВМ на интегральных схемах (начало 1960-ых - середина 1970-ых годов). Иногда интегральную схему называют - микросхемой или чипом (chip в переводе с английского - щепка). С 1965 г. был начат выпуск одной из лучших машин третьего поколения IBM/360, семейство этих машин состояло из семи моделей. Параллельно с компьютерами третьего поколения продолжали выпускаться компьютеры второго поколения - так, например, компьютеры «UNIVAC 494» выпускались до середины 1970-х годов.

Возникновение четвертого поколения ЭВМ связано с усовершенствованием ИС. В 1950 г. американский ученый К. Ларк-Горовиц (Lark-Horovitz) обратил внимание на возможность радиоактивного нейтронного легирования германия; в начале 1960-ых гг. Этот метод начали применять к кремнию, на сверхчистых пластинах которого методом интегральной технологии изготавливаются большие интегральные схемы (БИС) и сверхбольшие интегральные схемы (СБИС). Большие интегральные схемы было бы корректней назвать интегральными схемами с большой степенью интеграции; БИС содержит 1000-10000 элементов в кристалле полупроводника (обычно - на поверхности кристалла), СБИС - свыше 10000 элементов. Возникновение БИС и СБИС сделало возможным появление микропроцессоров.

В 1969 г. сотрудник компании Intel Маршиан Эдвард Хофф (Marcian Edward Hoff) )предложил создать центральный процессор на одном кристалле, что и было сделано в 1970 г.; это устройство получило название - микропроцессор. В 1971 году компания Intel выпускает на рынок первый микропроцессор Intel 4004 (он был четырехразрядным). Появление микропроцессоров позволило создать микрокомпьютеры - небольшие и недорогие, которые могли себе позволить купить маленькие компании и отдельные люди. В 1980-х годах микрокомпьютеры - персональные компьютеры (ПК) - стали повсеместным явлением.

Четвертое поколение - ЭВМ на больиих интегральных схемах (с середины 1970-ых годов). Ключевым моментом стало создание ПК.; после появления ПК Альтаир 8800 фирмы MITS (Micro Instrumentation and Telemetry Systems) в 1975 г., компьютеров Apple I и Apple II фирмы Apple Computer - в 1976 г. и в 1977 г. соответственно, и особенно знаменитого ПК ІВМ РС в 1981 г. персональные компьютеры покорили мир.

Иногда говорят о пятом поколении ЭВМ: на наш взгляд это некорректно, если разделять поколения ЭВМ по элементной базе (даже между третьим и четвертым поколениями грань весьма тонкая, но здесь можно говорить по крайней мере о появлении микропроцессоров и ПК). Сам термин «пятое поколение компьютеров» в настоящий момент является неопределенным и применяется во многих смыслах. Некоторые считают точкой отсчета для «пятого поколения» создание двухъядерного ПК (2005 г.).

Современное состояние и перспективы развития информационных технологий

Современный этап развития информационно-коммуникационных технологий характеризуется чрезвычайно быстрым (и почти одновременным!) развитием компьютерных сетей (особую роль сыграло возникновение всемирной сети Internet на основе которой работает Всемирная паутина - World Wide Web) и мобильной связи (в 1984 году пользователями мобильной связи было около 300 тыс. человек, а в 2003 - уже более чем 1,2 млрд.), причем современный мобильный телефон вобрал в себя, по сути дела, все функции персонального компьютера (смартфон). 


\section{ОГЛЯДИ ТА РЕКЛАМНІ МАТЕРІАЛИ}

Как сетевые компьютерные технологии, так и технологии мобильной связи (точнее - мобильной радиосвязи) постоянно совершенствуется, поэтому грядущие перемены на наш взгляд в краткосрочной перспективе вполне предсказуемы.

Если в настоящее время преобладают настольные (стационарные) ПК, которые постепенно вытесняются ноутбуками, лэптопами, ультрабуками и планшетными компьютерами (планшетами), то вскоре всех их заменят модернизированные смартфоны. Особую роль здесь должно сыграть появление гибких дисплеев, которые производятся в США и Японии по крайней мере с 2008 г. (хотя пока и в незначительных количествах). Однако, по целому ряду причин, сенсорный дисплей не сможет в ближайшем будущем полностью заменить мышь и клавиатуру.

Мобильная телефонная связь постепенно вытесняет кабельную, хотя последняя будет сохраняться еще долго (для надежности). Так же и проводные компьютерные сети постепенно будут вытеснены беспроводными, хотя кабельное телевидение может даже получить «второе дыхание» (по коммерческим и социальным причинам).

Сетевые технологии будут развиваться все интенсивнее (причем не только Internet-, но и Intranet-технологии, последний фактор диктуется учащающимися хакерскими атаками и необходимостью обеспечить должный уровень кибербезопасности и киберзащиты).

В сфере коммуникаций еще одним важным видоизменением в ближайшее время может стать почти полный отказ от современных почтовых услуг в пользу электронной почты (хотя курьерская доставка материальных ценностей естественно сохранится).

Следует ожидать совершенствования существуюих периферийных устройств компьютеров, которые и сейчас находятся на чрезвычайно высоком уровне (пример - 3D-принтеры или фабберы - устройства, использующие метод послойного создания трехмерного физического объекта по цифровой 3D-модели). К тому же появится и принципиально новая периферия.

Принципиальным прорывом в сфере hardware может стать создание компьютеров действительно нового (пятого!) поколения. На наш взгляд главные надежды в этом направлении связаны с оптическими (фотонными) компьютерами. Идея оптических (фотонных) вычислений - вычислений, производимых с помощью фотонов, которые сгенерированы лазерами или диодами - имеет достаточно давнюю историю. Преимущества очевидны: используя фотоны (движущиеся со скоростью света), возможно достигнуть несравнимо более высокой скорости передачи сигнала, чем используя электроны (как это имеет место в современных компьютерах). Эта идея стала обретать материальную силу после того, как в Массачусетском технологическом институте (США) в 1969 г. была предсказана, а в 1976 г. наблюдалась на опыте оптическая метастабильность. Для приборов, работающих на основе этого явления, требуется полупроводник, прозрачный в одной области спектра и непрозрачный в другой, с резко нелинейной оптической характеристикой (например, антимонид индия). Логические схемы на таких оптических элементах могут работать со скоростью 1000 млрд. логических операций в секунду. В настоящее время большинство разработчиков фокусируется на замене электронных компонентов современного компьютера на оптические эквиваленты, результатом чего является цифровая компьютерная система для обработки двоичных данных. Такой подход дает возможность в краткосрочной перспективе разработать технологии для коммерческого применения, поскольку оптические компоненты могут быть внедрены в стандартные компьютеры, создавая гибрид технологий. Однако опто-электронные приборы теряют 30\% энергии на конвертацию электронов в фотоны и обратно. Это также чрезвычайно замедляет передачу информации. В полностью оптическом компьютере необходимость преобразования сигнала из оптического в электронный и обратно в оптический отпадает. Первый макет оптического компьютера был создан в 1990 г. компанией Bell Laboratories (Bell Labs). Несколько лет назад компанией Lenslet был выпущен единственный на данный момент коммерческий оптический процессор EnLight256, особенность архитектуры которого состоит в том, что ядро основано на оптических технологиях, а все входы и выходы - электронные (процессор способен выполнять до $8 \times 10^{12}$ операций в секунду). В 2008 г. исследователи из компании IBM представили оптический коммутатор, который обеспечивает пакетную передачу данных со скоростью более 1 Тбит/с ); через год профессорами Массачусетского технологического института Владимиром Стояновичем и Радживом Ремом было предложено использовать для создания оптоэлектронных устройств, в том числе и оптических процессоров, обычный технологический процесс изготовления полупроводниковых процессоров, основанный на 32-нм технологии; в июле 2014 г. в Институте Вейцмана (Израиль) создан фотонный маршрутизатор - устройство, основанное на одном-единственном атоме (способном переключаться из одного квантового состояния в другое) и позволяющее направлять единичные кванты света по заданному маршруту, фотонный маршрутизатор - большой шаг на пути к созданию фотонных компьютеров будущего. 
Если оптические компьютеры вытеснят электронные, то слова «компьютер» и «ЭВМ» («электронновычислительная машина») перестанут быть синонимами, а инженеры-компьютерщики будут фокусировать свои научные интересы не на электронике, а на оптике и квантовой механике.

В сфере brainware возможные прорывы связаны с развитием математики - теории автоматов и тесно связанной с ней теории алгоритмов [16], теории вычислимости и теории вычислительной сложности. Теория автоматов и теория алгоритмов - разделы классической математической логики, в которых внимание сфокусировано на вопросе о том, что можно автоматизировать или вычислить; к теории алгоритмов примыкает теория вычислимости (теория рекурсивных функций). Теория вычислительной сложности (или теория сложности вычислений) - еще один раздел дискретной математики, тесно связанный с информатикой; основной вопрос этой теории - какое количество ресурсов необходимо для вычислений (если проблема вычислимости решена). Для многочисленных приложений особую роль приобретает развитие теории графов.

Сама математика (несмотря на присущий этой науке естественный консерватизм) также меняет направления своего развития под влиянием современных информационных технологий и компьютеров. Хотя Винер принципиально возражал против разделения математики на классическую и прикладную [17] (будучи полигистором, он вообще был убежден, что деление науки на различные дисциплины есть не более чем административная условность, необходимая лишь для удобства распределения сил и средств), такое разделение в настоящее время все же весьма ощутимо. В прикладной математике все более полагаются на численный эксперимент, используя именно его результаты в качестве критерия истины (в отличие от классической математики, где критерием истины является непротиворечивость); в некоторых случаях численные методы применяются без строгого доказательства их сходимости. Однако классическая математика сохраняет свое значение для решения фудаментальных проблем информатики и кибернетики (см. выше), для развития прикладной математики, а также для корректного применения ряда прикладных программных продуктов типа пакета MATLAB.

Для решения задач искусственного интеллекта, в частности для создания интеллектуальных систем поддержки принятия решений (ИСППР), все шире применяются нетрадиционные разделы математики - такие, как теория нечетких множеств и нечеткая логика [18-20], а также теория возможностей [21], хотя, если речь идет о принятии решений в условиях риска, решающее слово остается за теорией вероятностей.

В сфере software, судя по всему, еще длительное время будет сохраняться ориентация на объектноориентированное программирование (ООП) - с его событийной моделью - и объектно-ориентированный анализ (ООА) [22], хотя развитие аппаратной части компьютеров постоянно и с неизбежностью требует новых программных решений.

Системное программное обеспечение развивается и будет развиваться существенно более низкими темпами по сравнению с прикладным (наследие всеобщей компьютеризации).

Наконец, в сфере orgware, при постоянно возрастающей роли персональных ЭВМ в организационном управлении [23], особое внимание будет уделяться проблемам компьютерной безопасности (здесь, кстати, возникает множество вопросов в области права, ответов на которые нет до сих пор).

\section{Выводы}

Современные вычислительные системы и информационные технологии находят и будут находить все более широкое применение в самых разных областях человеческого бытия - в науке и технике, в образовании и культуре, в производстве, на транспорте и в сфере обслуживания. Они формируют стиль жизни современного человека, его культуру, восприятие мира и образ действий. Однако развитие этих технологий несет в себе немало опасностей (свежий пример - быстрое прототипирование пластмассового оружия на 3D-принтерах). Поэтому дальнейшее совершенствование информационно-коммуникационных средств должно идти рука об руку с гуманизацией общества, причем особую роль должна сыграть гуманизация образования.

\section{Литература}

1. Groth D. P., MacKie-Mason J. K. Why an informatics degree? Isn't computer science enough? // Communications of the ACM : New York, 2010. - V. 53. - P. 26-28. - DOI: 10.1145/1646353.1646364.;

2. Ляпунов А.А. Проблемы теоретической и прикладной кибернетики. - М.: Наука, 1980. - 336 с.;

3. Винер Н. Кибернетика, или управление и связь в животном и машине. - М.: Гл. ред. изданий для зарубежных стран издательства «НАУКА», 1983. - 345 с.;

4. Бриллюен Л. Наука и теория информации. - М.: Физматгиз, 1960. - 392 с.;

5. Бриллюен Л. Научная неопределенность и информация. - М.: Мир, 1966. - 271 с.;

6. Эшби У.Р. Введение в кибернетику. - М.: ИЛ, 1962. - 432 с.; 
7. Эшби У.Р. Конструкции мозга. - М.: ИЛ, 1962. - 398 с.;

8. Берг А.И. Кибернетика и общественные науки // Наука и жизнь, 1963. - № 2. - С. 12-16.;

9. Rosenblueth A., Wiener N., Bigelow J. Behavior, Purpose and Teleology // Philosophy of Science: Baltimore, 1943. - V.10, №10 - Рю 18-24.;

10. Ладанюк А.П. Основи системного аналізу: Навч. посібник. - Вінниця: Нова книга, 2004. - 176 с.;

11. Богданов А.А. Тектология (Всеобщая орг. наука): В 2-х кн. Кн.1 - М: Экономика, 1989. - 304 с.;

12. Богданов А.А. Тектология (Всеобщая орг. наука): В 2-х кн. Кн.2 - М: Экономика, 1989. - 351 с.;

13. Джордж Ф. Основы кибернетики. - М.: Радио и связь, 1984. -272 с.;

14. Ляпунов А.А. О некоторых общих вопросах кибернетики // Проблемы кибернетики /Под ред. А.А. Ляпунова. - М.: Физматгиз, 1958. - Вып. 1. - С. 5-22.;

15. Ляпунов А.А., Яблонский С.В. Теоретические проблемы кибернетики // Проблемы кибернетики /Под ред. А.А. Ляпунова. - М.: Физматгиз, 1963. - Вып. 9. - С. 5-22.;

16. Ершов Ю.Л. Математическая логика /Ю.Л. Ершов, Е.А.Палютин - М.: Наука. Гл. ред. физ.-мат. лит., 1987. -336 c.;

17. Винер Н. Я - математик. - М.: Наука, 1967. - 353 с.;

18. Заде Л. Понятие лингвистической переменной и его применение к принятию приближенных решений. М: Мир, 1976. - 165 с.;

19. Мелихов А.Н., Бернштейн Л.С., Коровин С.Я. Ситуационные советующие системы с нечеткой логикой. М.: Наука. Гл. ред. физ.-мат. лит., 1990. - 272 с.;

20. Энта Ё. Теория нечетких решений: Нечеткие множества и теория возможностей. Последние достижения /Под ред. Р.Р. Ягера. - М.: Радио и связь, 1986. Часть IV. Практические задачи. - С. 301-312.;

21. Пытьев Ю.П. Возможность. Элементы теории и применения. - М.: Едиториал УРСС, 2000. - 192 с.;

22. Шлеер С., Меллор С. Объектно-ориентированный анализ: Моделирование мира в состояниях. - К.: Диалектика, 1993. - 240 с.;

23. Иоффе А.Ф. Персональные ЭВМ в организационном управлении. - М.: Наука. Гл. ред. физ.-мат. лит., 1988. $-208 \mathrm{c}$.

\section{References}

1. Groth D. P., MacKie-Mason J. K. Why an informatics degree? Isn"t computer science enough? // Communications of the ACM : New York, 2010. - V. 53. - P. 26-28. - DOI:10.1145/1646353.1646364;

2. Lyapunov A.A. Problemy teoretycheskoy y prykladnoy kybernetyky. - M.: Nauka, 1980. -336 s.;

3. Vyner N. Kybernetyka, yly upravlenye y svyaz v zhyvotnom y mashyne. - M.: Hl. red. yzdanyy dlya zarubezhnykh stran yzdatel'stva «NAUKA», 1983. - 345 s.;

4. Bryllyuen L. Nauka y teoryya ynformatsyy. - M.: Fyzmathyz, 1960. - 392 s.;

5. Bryllyuen L. Nauchnaya neopredelennost' y ynformatsyya. - M.: Myr, 1966. - 271 s.;

6. Eshby U.R. Vvedenye v kybernetyku. - M.: YL, 1962. - 432 s.;

7. Eshby U.R. Konstruktsyy moz·ha. - M.: YL, 1962. - 398 s.;

8. Berh A.Y. Kybernetyka y obshchestvennye nauky // Nauka y zhyzn', 1963. - \# 2. - S. 12-16.;

9. Rosenblueth A., Wiener N., Bigelow J. Behavior, Purpose and Teleology // Philosophy of Science: Baltimore, 1943. - V.10, \#10 - Ryu 18-24.;

10. Ladanyuk A.P. Osnovy systemnoho analizu: Navch. posibnyk. - Vinnytsya: Nova knyha, 2004. - 176 s.;

11. Bohdanov A.A. Tektolohyya (Vseobshchaya orhanyzatsyonnaya nauka): V 2-kh kn. Kn.1 - M: Ekonomyka, 1989. $-304 \mathrm{s.}$

12. Bohdanov A.A. Tektolohyya (Vseobshchaya orhanyzatsyonnaya nauka): V 2-kh kn. Kn.2 - M: Ekonomyka, 1989. $-351 \mathrm{~s}$.;

13. Dzhordzh F. Osnovy kybernetyky. - M.: Radyo y svyaz, 1984. - 272 s.;

14. Lyapunov A.A. O nekotorykh obshchykh voprosakh kybernetyky // Problemy kybernetyky /Pod red. A.A. Lyapunova. - M.: Fyzmathyz, 1958. - Vyp. 1. - S. 5-22.;

15. Lyapunov A.A., Yablonskyy S.V. Teoretycheskye problemy kybernetyky // Problemy kybernetyky /Pod red. A.A. Lyapunova. - M.: Fyzmathyz, 1963. - Vyp. 9. - S. 5-22.;

16. Ershov Yu.L. Matematycheskaya lohyka /Yu.L. Ershov, E.A.Palyutyn - M.: Nauka. Hl. red. fyz.-mat. lyt., 1987. $336 \mathrm{s.}$;

17. Vyner N. Ya - matematyk. - M.: Nauka, 1967. - 353 s.;

18. Zade L. Ponyatye lynhvystycheskoy peremennoy y eho prymenenye k prynyatyyu pryblyzhennykh reshenyy. M: Myr, 1976. - 165 s.; 
19. Melykhov A.N., Bernshteyn L.S., Korovyn S.Ya. Sytuatsyonnye sovetuyushchye systemy s nechetkoy lohykoy.M.: Nauka. Hl. red. fyz.-mat. lyt., 1990. - 272 s.;

20. Enta E. Teoryya nechetkykh reshenyy: Nechetkye mnozhestva y teoryya vozmozhnostey. Poslednye dostyzhenyya /Pod red. R.R. Yahera. - M.: Radyo y svyaz', 1986. Chast' IV. Praktycheskye zadachy. - S. 301-312.;

21. Pyt'ev Yu.P. Vozmozhnost'. Elementy teoryy y prymenenyya. - M.: Edytoryal URSS, 2000. - 192 s.;

22. Shleer S., Mellor S. Obъektno-oryentyrovannyy analyz: Modelyrovanye myra v sostoyanyyakh. - K.: Dyalektyka, 1993. - $240 \mathrm{~s}$;

23. Yoffe A.F. Personal'nye EVM v orhanyzatsyonnom upravlenyy. - M.: Nauka. Hl. red. fyz.mat. lyt., 1988. - 208 s.

\title{
НАУКОМЕТРИЯ В РАМКАХ ЕВРОИНТЕГРАЦИОННЫХ ПРОЦЕССОВ УКРАИНЫ
}

\author{
Егоров B.6. ${ }^{1}$ \\ ${ }^{1}$ Одесская национальная академия пищевых технологий, Одесса \\ E-mail: yegorov-victor@mail.ru \\ ORCID: $\underline{0000-0003-4699-834 \mathrm{X}}$
}

Copyright (C) 2014 by author and the journal "Automation technological and business - processes”. This work is licensed under the Creative Commons Attribution International License (CC BY). http://creativecommons.org/licenses/by/4.0/

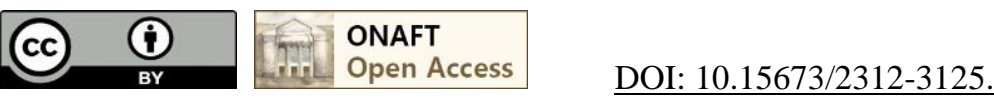

\begin{abstract}
Аннотация
Рассмотрены недостатки различных наукометрических показателей и спорность их необходимости. Рассмотрены недостатки наукометрических показателей, указано, что максимум внимания должно быть уделено непосредственно нивелированию их как таковых. Все подобные показатели можно условно разделить на 3 типа: основанные на количестве публикаций, основанные на количестве цитирований и комбинированные показатели (основаны на количестве цитирований и количестве публикаций одновременно).
\end{abstract}

\section{Abstract}

Shortcomings of various scientometric indicators and argumentativeness of their need are considered. Shortcomings of scientometric indicators are considered, is specified that a maximum of attention has to be paid directly to their leveling as those. All similar indicators can be divided into 3 types conditionally: the indicators based on number of publications, based on number of citings and combined (are based on number of citings and number of publications at the same time).

Ключевые слова

Наукометрия, наукометрические показатели, индексы цитирования, рефератиные базы данных, научные публикации

Введение. Ввиду непрерывно увеличивающегося количества ученых и сфер их научных изысканий все более актуальной проблемой становится поиск средств сравнения «успешности» ученых между собой. Сам факт вхождения ученого в Английское Королевское научное общество, например, или получение престижной, всемирно 